\title{
Measurement of inspiratory muscle performance with incremental threshold loading: a comparison of two techniques
}

\author{
P A Bardsley, S Bentley, H S Hall, S J Singh, D H Evans, M D L Morgan
}

\begin{abstract}
Background-Incremental threshold loading (ITL) is a test of inspiratory muscle performance which is usually performed by breathing through a weighted inspiratory plunger, the load on the inspiratory muscles being increased by externally adding weights to the intake valve. This is not a true threshold device and may be inaccurate. This method was compared with a true threshold device consisting of a solenoid valve which only opens to supply air at a predetermined negative mouth pressure.
\end{abstract}

Methods-Six naive, normal subjects (three men and three women) aged 22-24 years underwent three tests using each system. The inspiratory loads were increased every minute by equivalent amounts, $-10 \mathrm{~cm} \mathrm{H}_{2} \mathrm{O}$ with the solenoid valve and by $50 \mathrm{~g}$ with the weighted plunger, until the subjects could not inspire or sustain inspiration for a full minute. Six experienced subjects (four men and two women) aged 23-41 years were subsequently randomised to perform ITL with the solenoid valve, twice with the breathing pattern fixed and twice free.

Results-The solenoid valve generated a more accurate mouth pressure response and was less variable at higher loads than the weighted plunger. The work performed (expressed as the pressure-time product) was less with the solenoid valve but was more reproducible. ITL with the solenoid valve was not influenced by controlling the breathing pattern of the subjects.

Department of Respiratory Medicine, Glenfield General Hospital, Groby Road, Leicester LE3 9QP

P A Bardsley

S J Singh

M D L Morgan

Department of Medical Physics, University of Leicester $S$ Bentley

H S Hall

D H Evans

Reprint requests to:

Dr P A Bardsley

Received 10 July 1992

Returned to authors 22 October 1992 Revised version received 3 December 1992

Accepted 9 December 1992
Respiratory muscle performance can be assessed in terms of strength and endurance.
Strength can be measured as the maximum inspiratory and expiratory mouth pressures ${ }^{1}$ but measurement of respiratory muscle endurance is more difficult and cannot be inferred from measurements of strength. Three types of endurance tests are commonly used: maximum voluntary ventilation, resistive loading, and inspiratory threshold loading. ${ }^{2-4}$ Maximum voluntary ventilation is influenced by subject coordination, volition, and pulmonary mechanics as well as by respiratory muscle endurance. Since the role of the respiratory muscles is to generate pressure, techniques relating mouth pressures to resistances have been developed. It is possible to examine the endurance time for a particular load or to determine what maximum load can be tolerated for a specific time. Various resistive devices have been developed of which one of the most widely used is the weighted inspiratory plunger developed by Nickerson and Keens. ${ }^{4}$ A problem with all these devices is that the alteration of breathing pattern may influence measurement of respiratory muscle endurance. ${ }^{5}$ Fixing respiratory rate and generation of breath by breath pressure makes these tests cumbersome.

Martyn and colleagues, using the weighted inspiratory plunger, described a progressive incremental test in which inspiratory loads were increased every two minutes. ${ }^{6}$ They found incremental threshold loading (ITL) with this device, as with a progressive incremental exercise test, to be a simple and reproducible test of respiratory muscle performance which was uninfluenced by fixing breathing frequency. McElvaney and colleagues found that ITL with the weighted plunger was a more reproducible test of respiratory muscle performance than the endurance time for which a maximum load could be tolerated. ${ }^{7}$ The weighted inspiratory plunger is, however, not strictly a true threshold device and we have been concerned about both its accuracy and reproducibility. We have developed a true threshold device consisting of a solenoid valve which opens rapidly and completely to supply air only at a predetermined negative mouth pressure. We have compared our system of ITL with the weighted inspiratory plunger as modified by Martyn and colleagues ${ }^{6}$ and have examined the influence of varying breathing patterns on the performance of subjects with the solenoid valve. 


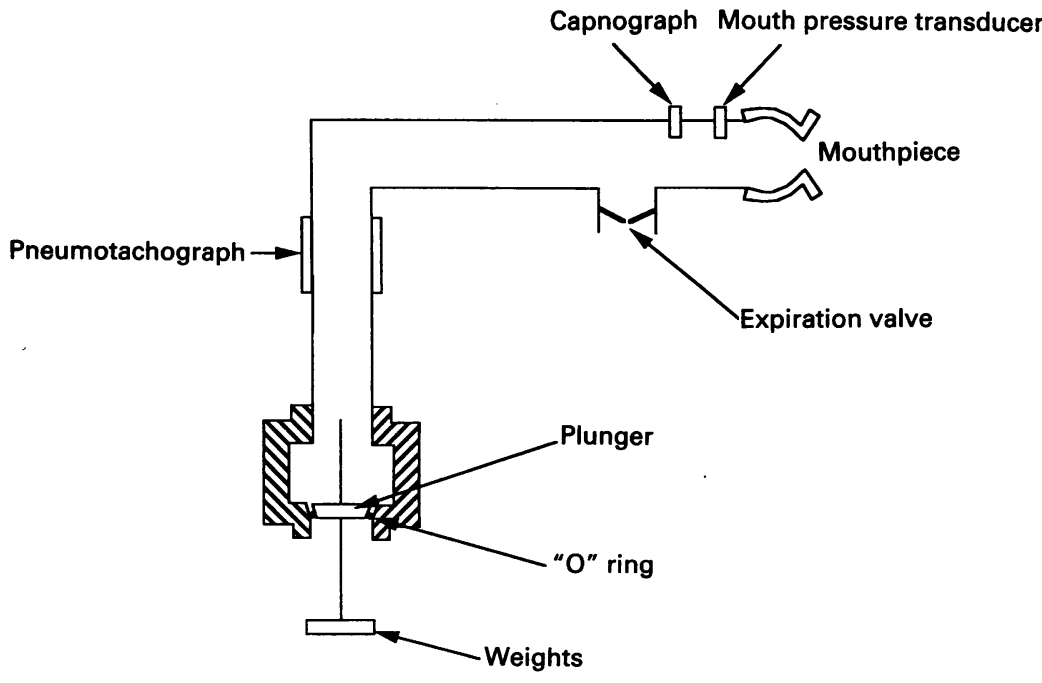

Figure 1 Diagram of the weighted inspiratory plunger.

\section{Methods}

WEIGHTED INSPIRATORY PLUNGER

The device consists of a plunger mounted over a large aperture (fig 1). The area of the plunger orifice at the point of contact, the " $O$ ring" is $4.9 \mathrm{~cm} .^{2}$ The plunger is mounted on a low friction bearing which allows it to rise to supply air when the pressure in the chamber, the threshold pressure (Pth), falls below atmospheric pressure by the amount $M \times g / A$ where $M$ is the mass of the plunger, $g$ is the gravitational constant, and $A$ is the area of the aperture. The negative pressure required to lift the plunger can be increased, without disrupting the system, by externally adding $50 \mathrm{~g}$ weights, equivalent to an increase in Pth of $-10 \mathrm{~cm} \mathrm{H}_{2} \mathrm{O}$.

\section{SOLENOID VALVE DEVICE}

The solenoid device consists of a wide bore 24 V DC solenoid valve which opens rapidly and completely when the required negative mouth pressure is achieved (opening time $28 \mathrm{~ms}$ and resistance $8 \mathrm{~Pa} / 1 / \mathrm{min}$ measured at a flow rate of $100 \mathrm{l} / \mathrm{min}$ ), closing on expiration (fig 2). The Pth can be selected on a digital display. A transducer amplifier (Gould model 13-4615-50) and P50 transducer were used to monitor the pressure in the mouthpiece. The output from the amplifier was fed into a display/alarm module (Gould model 13-4611-12). On inspiration when the mouth pressure reaches the value set on the low alarm control an internal relay is actuated, connecting $24 \mathrm{~V}$ from a Farnell L30 power supply to the solenoid valve via a latching circuit so holding the solenoid open. During expiration pressure in the mouthpiece rises, triggering the high pressure alarm which resets the latching circuit and closes the valve.

\section{EXPERIMENTAL PROTOCOL}

Comparison of the solenoid valve and weighted plunger

Six naive, healthy, normal, non-smoking subjects (three men and three women) aged 22-24 years with vital capacity (VC) 3.4-5.31 and maximum inspiratory pressure (PImax) 95-140 $\mathrm{cm} \mathrm{H}_{2} \mathrm{O}$ took part in the study. After giving informed consent subjects were seated in a hard backed chair, asked to wear a noseclip and to breathe through a mouthpiece. Inspiratory muscle strength was measured as PImax recorded during a maximal inspiration from residual volume by a modification of the method described by Black and Hyatt. ${ }^{1}$ The peak inspiratory mouth pressure sustained for one second was recorded and the best of three attempts taken.

All subjects underwent six tests on separate days and were randomised to perform incremental threshold loading three times with the plunger followed by three times with the solenoid valve or vice versa. Subjects started at an equivalent low inspiratory load: a Pth of $\mathbf{- 5}$ cm $\mathrm{H}_{2} \mathrm{O}$ with the solenoid valve and no added weights on the plunger (weight $25 \mathrm{~g}$ ). The load on the inspiratory muscles was then increased every minute either by $50 \mathrm{~g}$ with the weighted plunger or by $-10 \mathrm{~cm} \mathrm{H}_{2} \mathrm{O}$ with the solenoid valve until the subjects could no longer inspire or sustain the load for a full minute. The tests finished when the subject was unable to reach the Pth. At this point he
Figure 2 Diagram of the solenoid valve device.

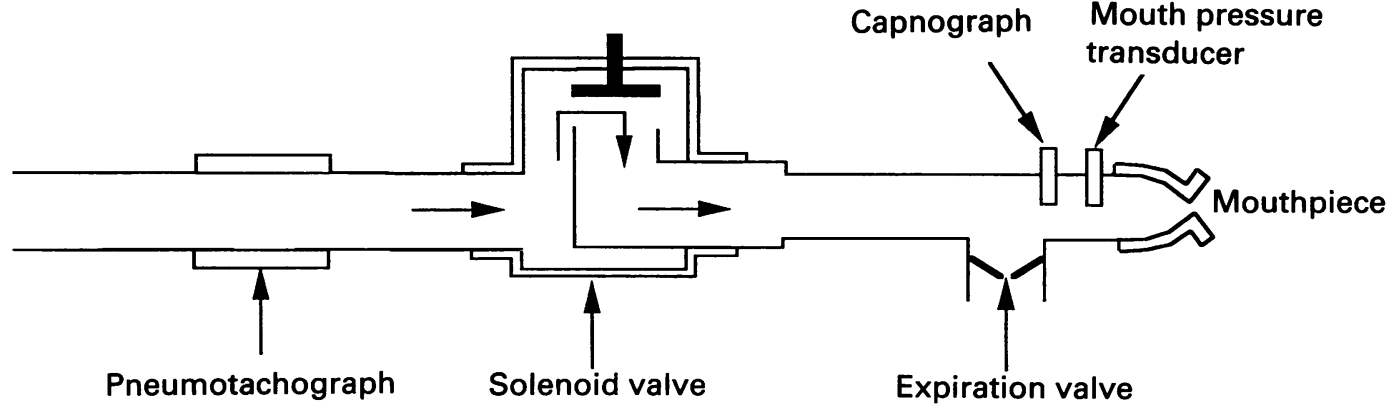

Solenoid

valve
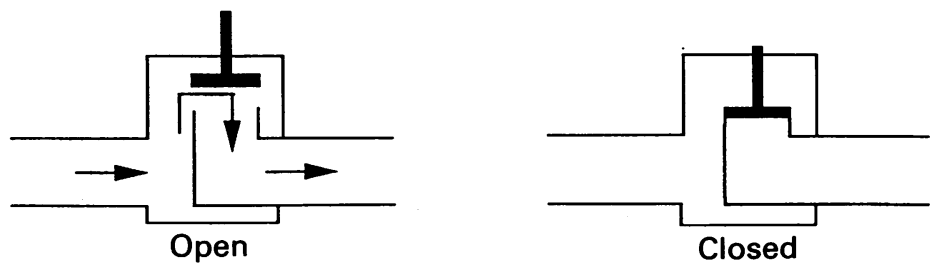
Solenoid valve

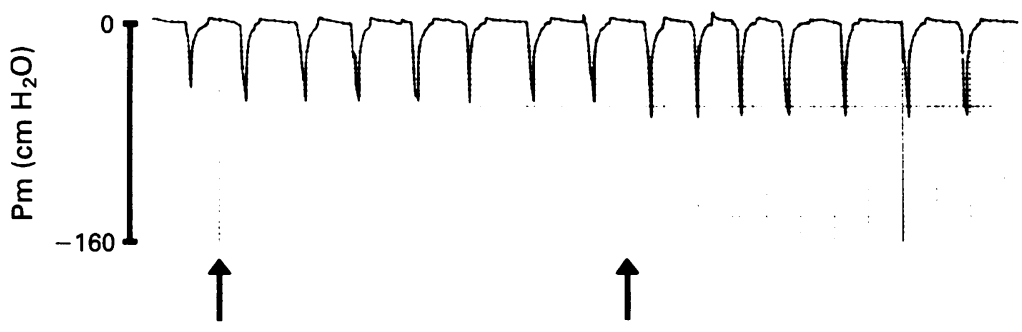

Weighted plunger

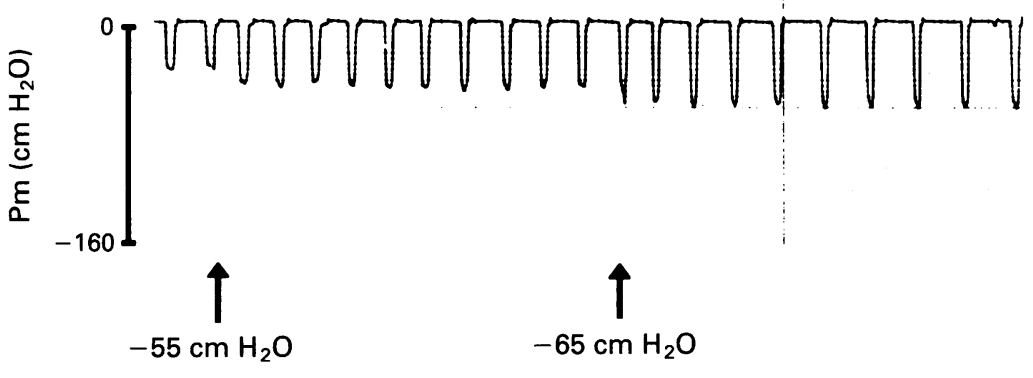

Pth

Figure 3 Example of the inspiratory pressure profile showing the mouth pressure trace (Pm) obtained with each system as the threshold pressure (Pth) was increased every minute by $-10 \mathrm{~cm} \mathrm{H}_{2} \mathrm{O}$. or she had to come off the mouthpiece. Subjects were free to stop the test at any stage simply by removing the mouthpiece. Expiration was not loaded. Breathing rate and pattern were not regulated and no encouragement was given although competition between subjects was encouraged.

During each test we recorded the breath by breath mouth pressure (Pm) achieved to overcome the threshold load and the pressure-time product ( $\left.\int \mathrm{Pdt}\right)$ obtained by integrating $\mathrm{Pm}$ with respect to time. Inspiratory flow was measured through a pneumotachograph. All subjects scored their degree of res-

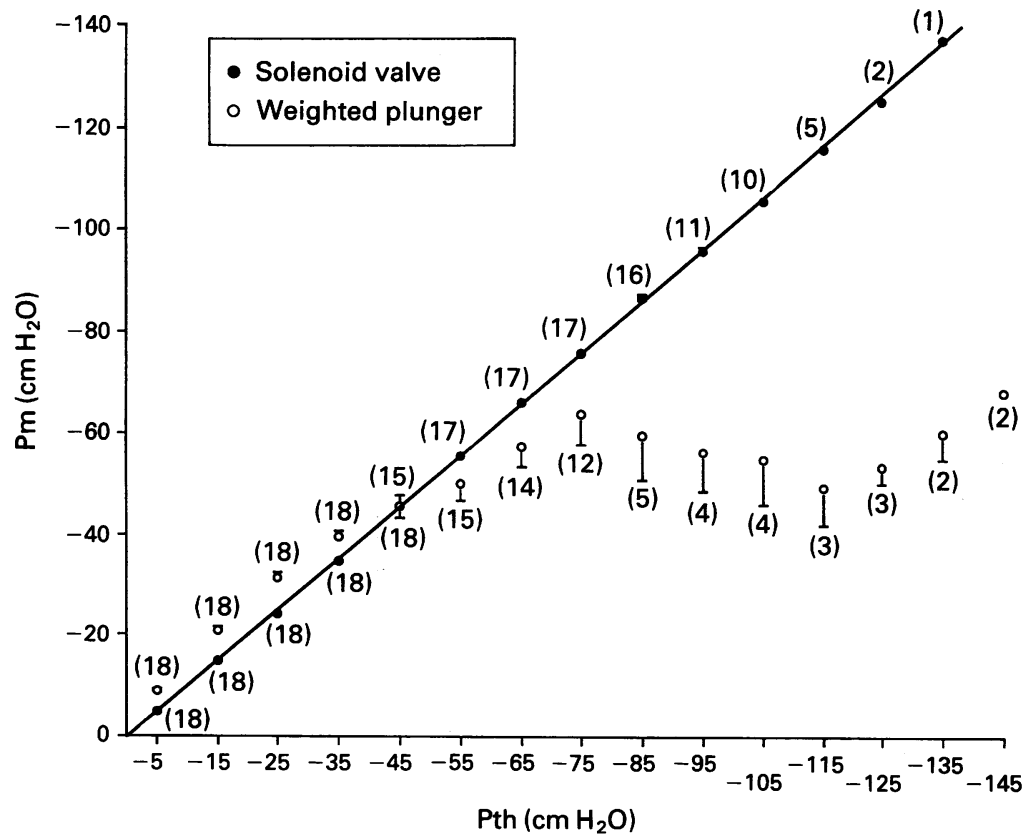

Figure 4 Mouth pressure (Pm) plotted against threshold pressure (Pth) for all the tests with both systems. The figures in parentheses refer to the number of values for each point. $A$ line of identity has been drawn to describe the ideal relationship between Pm and Pth. piratory effort on a modified Borg scale $(0-10)$ and their end tidal carbon dioxide concentration $\left(\mathrm{PETCO}_{2}\right)$ was recorded on an infrared $\mathrm{CO}$ analyser (model Engstrom Eliza $M C)$. The signals of inspiratory flow and volume, Pm, and JPdt were recorded continuously on a strip chart recorder (Gould model Brush 260). Breathing frequency and respiratory cycle duration (TTOT) could then be calculated. The time of inspiratory effort (TI) was measured from the mouth pressure recordings and the duty cycle (TI/TTOT) calculated. For each threshold load Pm was taken as the mean of the peak value of the last three breaths in each minute. Pm achieved with the largest load tolerated for one minute was taken as the peak mouth pressure.

\section{Influence of breathing pattern}

Six different normal subjects (four men and two women) aged 23-41 years with VC 4.0-6.0 1 and PImax 68-165 $\mathrm{cm} \mathrm{H}_{2} \mathrm{O}$ were studied. All had previous experience of the solenoid valve. They were randomised to perform ITL with the solenoid valve according to the protocol described above, twice with the breathing pattern fixed and twice when they were free to adopt whatever pattern of breathing they chose. During the regulated ITL tests breathing frequency was fixed at 12 breaths per minute using a breathing synchroniser and the mouth pressure trace was displayed on a digital storage oscilloscope (Gould model OS4040). Subjects maintained a constant breathing pattern by visual feedback. TTOT was equivalent to one sweep of the oscilloscope screen and, to keep TI constant, subjects were requested to inspire until the beam passed a cursor placed on the oscilloscope screen. TI for each subject was chosen before their first regulated ITL test by establishing a pattern of breathing that felt comfortable. Subjects were then asked to adhere to this target throughout the regulated ITL tests.

ANALYSIS

The results, presented as mean (SE), were analysed with the Minitab Version 8 statistical package for IBM computers. Data obtained from the ITL tests with the plunger and solenoid valve were compared with the Wilcoxon signed rank test. A p value $<0.05$ was considered significant. Agreement between tests was assessed according to the recommendations of Bland and Altman. ${ }^{8}$

This study was approved by the hospital ethics committee.

\section{Results}

COMPARISON OF THE SOLENOID VALVE AND WEIGHTED PLUNGER

Examples of the inspiratory pressure profiles obtained during incremental threshold loading with each system are shown in fig 3 . Figure 4 shows the mean mouth pressure (Pm) plotted against the threshold pressure (Pth) for all the tests with both the weighted plunger and the solenoid valve. At lower 


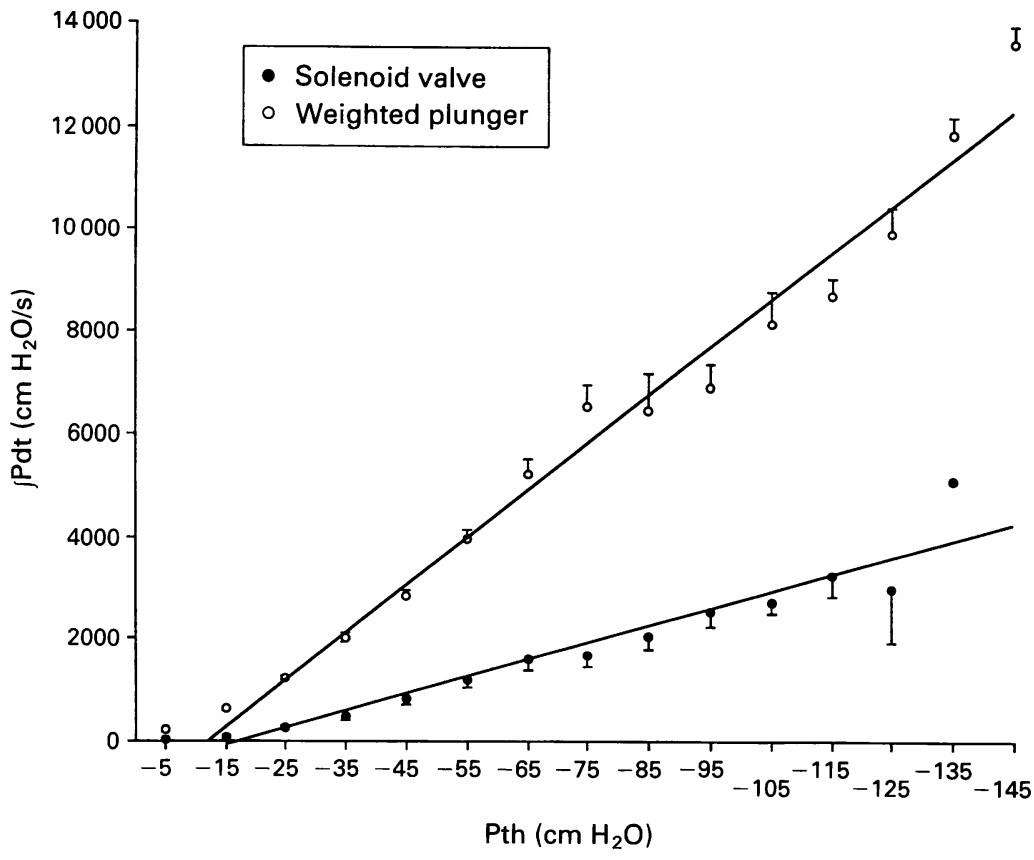

Figure 5 Work performed by the inspiratory muscles expressed as the pressure-time product ( $(P d t)$ plotted against the threshold pressure (Pth) for all the tests with both systems. Linear regression lines have been drawn $(p<0.05$ for both the solenoid valve and weighted plunger).

Table 1 Mean (SE) values of length of time of the tests ( $t$ ), final mouth pressure (peak $\mathrm{Pm}$ ) and percentage of maximal inspiratory pressure (Pm/PImax) achieved and pressure-time product $\left(\int P d t\right)$ at completion of the tests.

\begin{tabular}{|c|c|c|c|c|}
\hline & $t$ (min) & $\begin{array}{l}\text { Peak Pm } \\
\left(\mathrm{cm} \mathrm{H} \mathrm{H}_{2} \mathrm{O}\right)\end{array}$ & $\begin{array}{l}\mathrm{Pm} / \mathrm{PI} \max \\
(\%)\end{array}$ & $\begin{array}{l}\int P d t \\
\left(\mathrm{~cm} \mathrm{H} \mathrm{H}_{2} \mathrm{O} / \mathrm{s}\right)\end{array}$ \\
\hline \multicolumn{5}{|l|}{ Solenoid valve } \\
\hline 1 & $8 \cdot 0(1 \cdot 1)$ & $-76 \cdot 3(10 \cdot 9)$ & $73.5(6.2)$ & $2882(584)$ \\
\hline 2 & $9.7(0.9)$ & $-93.8(10 \cdot 2)$ & $86.8(3.7)$ & $2910(341)$ \\
\hline 3 & $10 \cdot 5(1.2)$ & $-100 \cdot 5(12 \cdot 1)$ & $89 \cdot 7(7 \cdot 6)$ & $2970(496)$ \\
\hline \multicolumn{5}{|l|}{ Weighted plunger } \\
\hline 1 & $7 \cdot 7(1 \cdot 9)$ & $-60 \cdot 7(8 \cdot 5)$ & $57 \cdot 0(2 \cdot 7)$ & $6718(1993)$ \\
\hline 2 & $8 \cdot 8(1 \cdot 3)$ & $-59.5(7 \cdot 3)$ & $56.3(2.9)$ & 7573 (1449) \\
\hline 3 & $8.7(0.9)$ & $-67 \cdot 0(7 \cdot 8)$ & $60 \cdot 3(3 \cdot 5)$ & $7307(485)$ \\
\hline
\end{tabular}

Table 2 Mean differences (95\% confidence intervals) for length of time of tests ( $t$ ), final mouth pressure achieved (peak Pm) and pressure-time product $(\oint P d t)$ at completion of tests.

\begin{tabular}{|c|c|c|c|}
\hline & $t(\min )$ & Peak Pm $\left(\mathrm{cm} \mathrm{H}_{2} \mathrm{O}\right)$ & $\int P d t\left(c m H_{2} \mathrm{O} / \mathrm{s}\right)$ \\
\hline $\begin{array}{l}\text { Solenoid valve } \\
1 v 2 \\
2 v 3 \\
1 v 3\end{array}$ & $\begin{array}{l}-1 \cdot 7(-3 \cdot 6,0 \cdot 3) \\
-0 \cdot 8(-1 \cdot 6,0 \cdot 0) \\
-2 \cdot 5(-5 \cdot 0,0 \cdot 0)\end{array}$ & $\begin{array}{l}-17 \cdot 5(-35 \cdot 2,0 \cdot 21) \\
-6 \cdot 7(-15 \cdot 3,2 \cdot 0) \\
-24 \cdot 2(-47 \cdot 9,-0 \cdot 5)\end{array}$ & $\begin{array}{l}-28 \cdot 3(-1600,1540) \\
-60 \cdot 0(-850,732) \\
-88 \cdot 3(-2200,2070)\end{array}$ \\
\hline $\begin{array}{l}\text { Weighted plunger } \\
\begin{array}{l}1 v 2 \\
2 v 2 \\
1 v 3\end{array}\end{array}$ & $\begin{array}{r}-1 \cdot 2(-3 \cdot 5,1 \cdot 2) \\
0 \cdot 2(-4 \cdot 3,4 \cdot 6) \\
-1 \cdot 0(-6 \cdot 9,4 \cdot 9)\end{array}$ & $\begin{aligned} 1 \cdot 2 & (-5 \cdot 8,8 \cdot 1) \\
-7 \cdot 5 & (-14 \cdot 2,-0 \cdot 8) \\
-6 \cdot 3 & (-17 \cdot 5,4 \cdot 8)\end{aligned}$ & $\begin{array}{l}-855(-3100,1419) \\
-267(-3500,4073) \\
-588(-6000,4791)\end{array}$ \\
\hline
\end{tabular}

Table 3 Mean (SE) breathing frequency, inspiratory time (TI), duty cycle (TI/TTOT), and end tidal carbon dioxide concentration $\left(\mathrm{PET} \mathrm{CO}_{2}\right)$ at the start and end of the tests with solenoid valve and weighted plunger.

\begin{tabular}{|c|c|c|c|c|}
\hline & \multicolumn{2}{|l|}{ Solenoid valve } & \multicolumn{2}{|c|}{ Weighted plunger } \\
\hline & Start & End & Start & End \\
\hline \multicolumn{5}{|l|}{ Breathing frequency } \\
\hline $\begin{array}{l}\text { (breaths/min) } \\
\operatorname{TI}(\mathrm{s})\end{array}$ & $\begin{array}{r}10 \cdot 8(1 \cdot 2) \\
2 \cdot 5(0.3)\end{array}$ & & $\begin{array}{r}12 \cdot 5(1 \cdot 3) \\
2 \cdot 4(0 \cdot 3)\end{array}$ & $\begin{array}{r}11 \cdot 5(1 \cdot 8) \\
3 \cdot 7(0 \cdot 6)\end{array}$ \\
\hline ТІ/Ттот & $0.38(0.04)$ & $0.38(0.08)$ & $0.44(0.03)$ & $0.62(0.04)$ \\
\hline PET CO $2(\mathrm{kPa})$ & $4 \cdot 6(0 \cdot 2)$ & $3 \cdot 8(0 \cdot 2)$ & $5 \cdot 2(0 \cdot 2)$ & $5 \cdot 7(0 \cdot 2)$ \\
\hline
\end{tabular}

inspiratory loads there was good correlation between $\mathrm{Pm}$ achieved and inspiratory load applied using both systems. At a Pth above $-75 \mathrm{~cm} \mathrm{H}_{2} \mathrm{O}$, however, equivalent to an added plunger weight of $350 \mathrm{~g}$, there was much wider variation in recorded mouth pressures with the weighted plunger $(r=$ $0 \cdot 82)$. With the solenoid valve the correlation remained tight throughout $(r=1.00) ; 95 \%$ confidence intervals (CIs) at equivalent stages in the tests were $23 \cdot 3-25 \cdot 3 \mathrm{~cm} \mathrm{H}_{2} \mathrm{O}$ with a Pth of $-25 \mathrm{~cm} \mathrm{H}_{2} \mathrm{O}$ with the solenoid valve and 29.8-33.2 cm $\mathrm{H}_{2} \mathrm{O}$ with an added plunger weight of $100 \mathrm{~g}$. At a solenoid Pth of $-75 \mathrm{~cm} \mathrm{H}_{2} \mathrm{O} 95 \%$ CIs were 74.7-76.9 cm $\mathrm{H}_{2} \mathrm{O}$ and with an added plunger weight of $350 \mathrm{~g}$ they were $50 \cdot 4-77 \cdot 3 \mathrm{~cm} \mathrm{H}_{2} \mathrm{O}$.

The $\int \mathrm{Pdt}$ which gives an index of the external work performed by the inspiratory muscles during loaded breathing ${ }^{9}$ increased much more steeply with the weighted plunger although for both systems increments were regular (fig 5).

The reproducibility of both systems in terms of length of time of the test $(t)$, peak $\mathrm{Pm}$, percentage of PImax achieved and P Pdt at completion of the test is shown in table 1 . Table 2 gives the mean differences and $95 \%$ CIs for the various attempts at ITL using both systems.

We compared breathing patterns during the third test with each system (table 3). With the solenoid valve breathing frequency slowed significantly during the tests $(p<0.05)$ but both $T_{I}$ and TI/TTOT did not alter. With the weighted plunger breathing frequency did not alter but subjects tended to prolong TI $(\mathrm{p}>0.05)$ and so increase TI/TTOT $(\mathrm{p}<0.05) . \mathrm{PETCO}_{2}$ tended to be significantly lower during the tests with the solenoid valve ( $p<0.05$ comparing values between the two systems at the end of the tests). No difference in Borg score was recorded. The median score at the end of the test was 9 with the solenoid and 9 with the plunger.

INFLUENCE OF BREATHING PATTERN

When breathing pattern was unregulated subjects performing ITL tests with the solenoid valve tended to reduce breathing frequency and to shorten the duty cycle (table 4 ). There was, however, no significant difference between the regulated and unregulated tests with respect to the duration of the tests, peak $\mathrm{Pm}$, \%PImax, final Pdt achieved, $\mathrm{PETCO}_{2}$, or Borg score (table 5). Mean differences and 95\% CIs between the tests with the breathing pattern free were $-0.2(-1.7,1.3)$ for the length of time of the test, $-1 \cdot 7(-17 \cdot 1,13 \cdot 8)$ for peak Pm, and $566(-631,1764)$ for $\int \mathrm{Pdt}$. With the breathing pattern regulated these values were $-1 \cdot 7,(-2 \cdot 4,0 \cdot 1),-11 \cdot 7(-23 \cdot 9$, $0 \cdot 6)$ and $-243(-1200,724)$ respectively.

\section{Discussion}

Incremental threshold loading possesses many qualities of a good test of respiratory muscle performance. As well as being influenced by inspiratory muscle strength it also 
Table 4 Mean (SE) breathing frequency, inspiratory time (TI) and duty cycle (TI/TTOT) at the start and end of regulated and unregulated tests with the solenoid valve.

\begin{tabular}{|c|c|c|c|c|c|}
\hline & \multicolumn{2}{|c|}{$\begin{array}{l}\text { Breathing pattern } \\
\text { free }\end{array}$} & \multicolumn{2}{|c|}{$\begin{array}{l}\text { Breathing pattern } \\
\text { regulated }\end{array}$} & \multirow[b]{2}{*}{$p$ value } \\
\hline & Start & End & Start & End & \\
\hline $\begin{array}{l}\text { Breathing frequency } \\
\text { (breaths/min) } \\
\text { TI } \\
\text { ТІ/Ттот }\end{array}$ & $\begin{array}{l}13.8(1.8) \\
1.5(0.2) \\
0.30(0.03)\end{array}$ & $\begin{array}{l}6.7(0.9) \\
1.8(0.1) \\
0.21(0.02)\end{array}$ & $\begin{array}{l}12 \cdot 2(0.5) \\
1.5(0.2) \\
0.32(0.04)\end{array}$ & $\begin{array}{l}11.3(0.4) \\
1.8(0.2) \\
0.34(0.03)\end{array}$ & $\begin{array}{l}<0.05 \\
\text { NS } \\
\text { NS }\end{array}$ \\
\hline
\end{tabular}

$p$ value refers to comparisons at end of tests.

Table 5 Mean (SE) values for length of time of test ( $t$ ), final mouth pressure achieved (peak $\mathrm{Pm}$ ), percentage of maximal inspiratory pressure (\%PImax), pressure-time product ( $P d t)$, end tidal carbon dioxide concentration $\left(\mathrm{PET} \mathrm{CO}_{2}\right)$, and Borg score at the completion of the tests.

\begin{tabular}{|c|c|c|c|c|}
\hline \multirow[b]{2}{*}{$\therefore$} & \multicolumn{2}{|c|}{$\begin{array}{l}\text { Breathing pattern } \\
\text { free }\end{array}$} & \multicolumn{2}{|c|}{$\begin{array}{l}\text { Breathing pattern } \\
\text { regulated }\end{array}$} \\
\hline & Test 1 & Test 2 & Test 1 & Test 2 \\
\hline $\begin{array}{l}t(\min ) \\
\text { Peak Pm }\left(\mathrm{cm} \mathrm{H}_{2} \mathrm{O}\right) \\
\% \text { PImax } \\
\int \mathrm{Pdt}\left(\mathrm{cm} \mathrm{H}_{2} \mathrm{O} / \mathrm{s}\right) \\
\text { PET } \mathrm{CO}_{2}(\mathrm{kPa}) \\
\text { Median Borg score }\end{array}$ & $\begin{array}{c}10 \cdot 8(2 \cdot 0) \\
-103(20) \\
90(8) \\
3478(944) \\
3.7(0 \cdot 2) \\
8\end{array}$ & $\begin{array}{c}11 \cdot 0(1 \cdot 6) \\
-105(16) \\
99(7) \\
2912(704) \\
4 \cdot 2(0 \cdot 3) \\
8\end{array}$ & $\begin{array}{c}8.8(1.5) \\
-83(15) \\
76(9) \\
2578(751) \\
3.4(0.4) \\
6\end{array}$ & $\begin{array}{c}10 \cdot 0(1 \cdot 6) \\
-95(16) \\
91(11) \\
2822(734) \\
3.4(0.3) \\
7\end{array}$ \\
\hline
\end{tabular}

measures maximal performance over a period of time thereby assessing endurance. The best way of performing ITL has not been determined. The two pieces of apparatus used in this study are different. The weighted plunger is not a true threshold device in that once the Pth has been achieved subsequent airflow is not totally independent of mouth pressure. The plunger must be held up throughout inspiration for the subject to receive sufficient airflow. In contrast the solenoid valve is a true threshold device in that once the subject has reached the predetermined negative mouth pressure the valve will remain open throughout the whole of inspiration regardless of subsequent pressure changes. The solenoid valve provides an isometric load to inspiratory muscle contraction and the weighted plunger an isotonic one.

Our concerns over the accuracy of the weighted plunger were confirmed by this study. At low loads there was a linear relationship between the plunger weight and subsequent mouth pressure achieved to overcome the threshold load. This relationship did not hold at weights above $350 \mathrm{~g}$ (equivalent Pth $-75 \mathrm{~cm} \mathrm{H}_{2} \mathrm{O}$ ) where there was wide intersubject and individual variation in recorded mouth pressures for any given load, probably due to the plunger only lifting partially, giving an added resistive load to inspiration. In contrast with the solenoid device, as one would expect there was a close correlation between the threshold pressure set and mouth pressure achieved. The achieved mouth pressure was usually a few $\mathrm{cm} \mathrm{H}_{2} \mathrm{O}$ higher than the set threshold pressure. This relationship was still evident at high loads. The increases in applied load with the solenoid device were smoother, quicker to perform, and more acceptable to the subject.

The pressure-time product, an index of the oxygen cost of breathing and external work performed by the inspiratory muscles, increased more steeply with the weighted plunger than the solenoid valve but both systems produced regular increments in the work performed. The pressure-time product at the end of the tests was substantially more with the plunger, a reflection of the extra work required for the inspiratory muscles to keep the plunger lifted throughout inspiration. At the end of the tests both $T_{I}$ and TI/TTOT were greater with the weighted plunger than with the solenoid valve.

There was an evident learning effect as subjects became familiar with both pieces of apparatus. The learning effect was more noticeable between the first and second tests with each device. After one practice ITL run both systems gave reproducible results regarding the duration of the tests, peak mouth pressure achieved, and total external work performed by the inspiratory muscles. The external work performed by the end of the tests was more reproducible with the solenoid valve than with the weighted plunger.

By starting with low loads during ITL subjects may develop breathing strategies to enable them to tolerate higher loads. This may interfere with the reproducibility of the test and interpretation of results, particularly when assessing the result of an intervention such as inspiratory muscle training. The strategies adopted during ITL with the two devices in this study were clearly different. With increasing loads on the weighted plunger subjects tended to prolong inspiratory time and to lengthen the duty cycle while breathing frequency tended not to change. With the solenoid valve subjects tended to slow their breathing frequency but not alter inspiratory time to limit the increase in the pressure-time product. We have shown that the performance of subjects during ITL runs with the solenoid valve is not significantly altered when both breathing frequency and inspiratory time are fixed, implying that varying breathing patterns are relatively unimportant to the reproducibility of the test. This means that ITL with the solenoid valve does not need any external regulation, so simplifying the test.

With both the weighted plunger and solenoid valve there was a clear endpoint to the tests. Most subjects complained of dyspnoea, a suffocating sensation, and pain in the neck and shoulders at the end of the test. Most felt hot and tired but recovered within a few minutes of resting. There was no qualitative or quantitative difference in these sensations between the systems.

Many authors relate inspiratory muscle endurance to fatigue. These tests may have been limited by respiratory muscle fatigue but we did not look specifically for this. It is likely to have occurred, however, as respiratory muscle fatigue has been shown to occur during the application of loads of $60-75 \%$ of those producing PImax. ${ }^{10}$ In our series of ITL runs the final mouth pressure achieved, particularly with the solenoid valve, was usually 
well above this value. The tests were probably also limited by motivation. No encouragement was given but competition between subjects was encouraged. The limit to the performance of the test may be due to subjects reaching the capacity of their inspiratory muscles or the limit of their tolerance to the unpleasant sensations associated with loading of the ventilatory muscles. Whatever the limiting factor(s) the endpoint of the tests with both systems was reproducible.

In conclusion, ITL is a simple and reproducible test of inspiratory muscle performance. The solenoid valve has several features which make it superior to the weighted inspiratory plunger. It generates a more accurate mouth pressure response and is less variable at higher loads. The increases in load are smoother and quicker to introduce. ITL with the solenoid valve is not influenced by varying breathing strategies and does not need any external regulation.
1 Black LF, Hyatt RE. Maximal static respiratory pressure in generalised neuromuscular disease. Am Rev Respir Dis 1971;103:641-50.

2 Freedman S. Sustained maximum voluntary ventilation. Respir Physiol 1970;8:230-44.

3 Roussos CS, Macklem PT. Diaphragmatic fatigue in man. f Appl Physiol 1977;43:189-97.

4 Nickerson BG, Keens TG. Measuring ventilatory muscle endurance in humans as sustainable inspiratory pressure. F Appl Physiol 1982;52:768-72.

5 Clanton TL, Dixon GF, Drake J, Gadek JE. Effects of breathing pattern on inspiratory muscle endurance in humans. F Appl Physiol 1985;59:1834-41.

6 Martyn JB, Moreno RH, Paré PD, Pardy RL. Measurement of inspiratory muscle performance with incremental threshold loading. Am Rev Respir Dis 1987;135:919-23.

7 McElvaney G, Fairbarn MS, Wilcox PG, Pardy RL Comparison of two-minute incremental threshold loading and maximal loading as measures of respiratory muscle endurance. Chest 1989;96:557-63.

8 Bland JM, Altman DG. Statistical methods for assessing agreement between two methods of clinical measurement. Lancet 1986;i:307-10.

9 Collett PW, Perry C, Engel LA. Pressure-time product, flow and oxygen cost of resistive breathing in humans. f Appl Physiol 1985;58:1263-72.

10 Roussos C, Fixley M, Gross D, Macklem PT. Fatigue of inspiratory muscles and their synergic behaviour. $\mathcal{F} A p p l$ Physiol 1979;46:897-904. 